\title{
Traumatic aneurysm of the cortical middle cerebral artery
}

\author{
Shivesh Varma, Lisa Banh, Paul Smith
}

Department of Neurosurgery, St Vincent's Hospital Melbourne, Fitzroy, Victoria, Australia

\section{Correspondence to} Dr Shivesh Varma, shivesh. varma@gmail.com

Accepted 7 February 2017

\section{(a) CrossMark}

To cite: Varma S, Banh $L$, Smith P. BMJ Case Rep Published online: [please include Day Month Year] doi:10.1136/bcr-2017219301

\section{DESCRIPTION}

A right-handed man aged 79 years presented with increasing confusion following a mechanical fall with head strike 2 weeks prior. CT demonstrated a left frontoparietal convexity subacute subdural haematoma (SDH) measuring $3 \mathrm{~mm}$ in depth and with $5 \mathrm{~mm}$ of midline shift to the right (figure 1). There was no skull fracture. Initial examination revealed no localising neurological deficit and he was admitted for observation. On day 3, the patient developed intermittent episodes of rightsided weakness and expressive dysphasia. Contrast MRI showed expansion of the SDH to $10 \mathrm{~mm}$ in thickness, and also demonstrated a $9 \mathrm{~mm}$ vividly enhancing focus within the haematoma overlying the frontal lobe (figure 2). The lesion enhanced on the arterial and venous phases of contrast CT (figure 3). Digital subtraction angiography demonstrated the lesion to be a $6 \mathrm{~mm}$ sidewall aneurysm of the cortical middle cerebral artery (MCA) (figure 4). Craniotomy was performed, the aneurysm trapped and excised with preservation of distal blood flow, and the SDH evacuated (figure 5). Histology demonstrated a lack of a tunica media or adventitia, consistent with pseudoaneurysm. The patient had mild residual weakness but otherwise recovered well and was transferred for rehabilitation.

Traumatic intracranial aneurysms (TICA) account for only $1 \%$ of intracranial aneurysms, but are

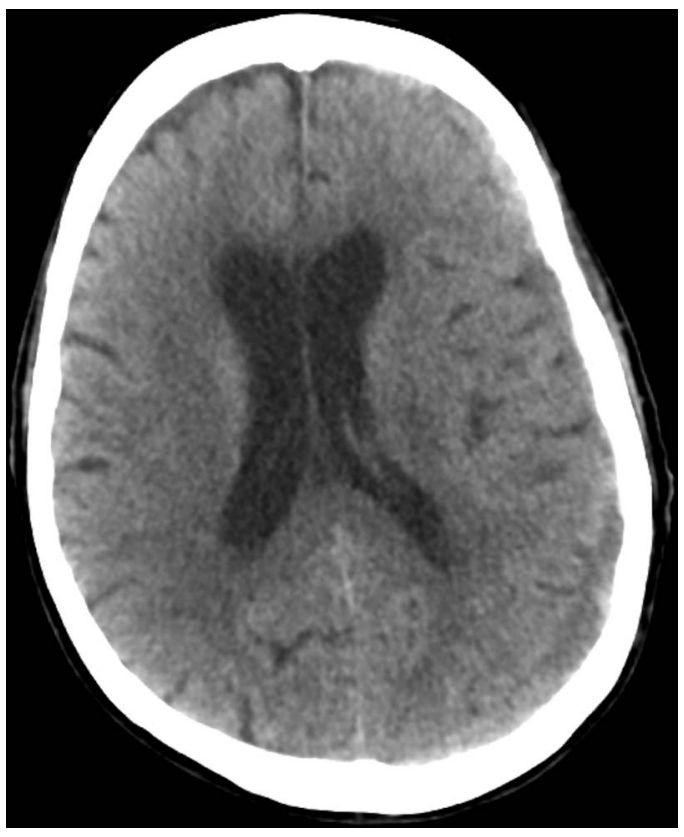

Figure 1 Initial CT of the brain at presentation showing the left subacute subdural haematoma. important because of their propensity to cause delayed bleeding. Several mechanisms can result in TICA, including closed blunt head trauma, missile injury, penetrating injury and iatrogenic injury. ${ }^{1}$ The average time from traumatic injury to haemorrhage from a TICA is 21 days, and in those with ruptured aneurysms, mortality has been reported to approach $50 \% .^{2}$

Traumatic middle cerebral artery aneurysms (TMCAA) are a subtype of TICA and in 93\% of cases occur in the cortical segment of the MCA,

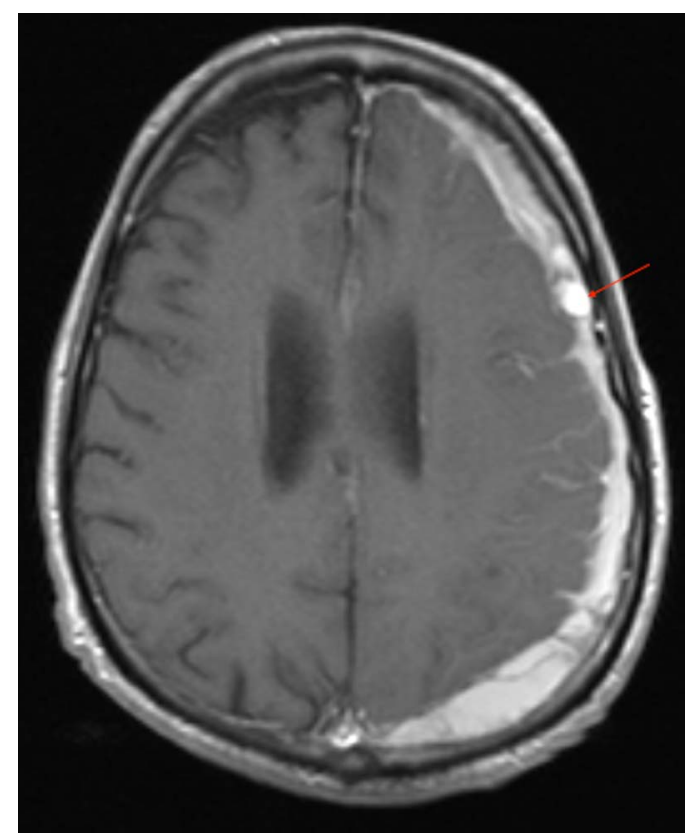

Figure 2 Contrast MRI at day 3 with enlarged subdural haematoma, and enhancing aneurysm (arrow).

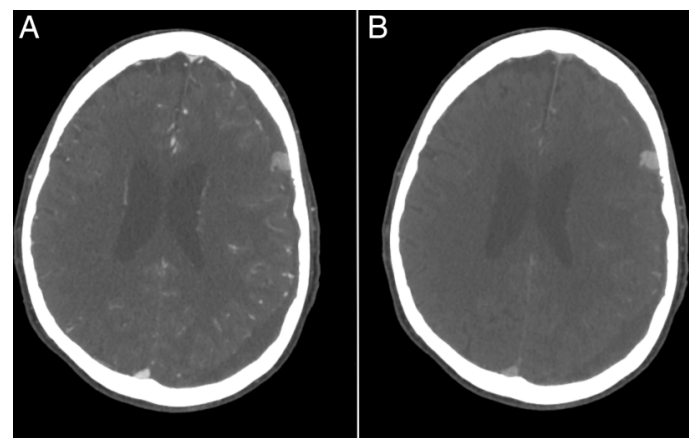

Figure 3 (A) Arterial and (B) venous phases of contrast-enhanced $\mathrm{CT}$ of the brain demonstrating aneurysm. 


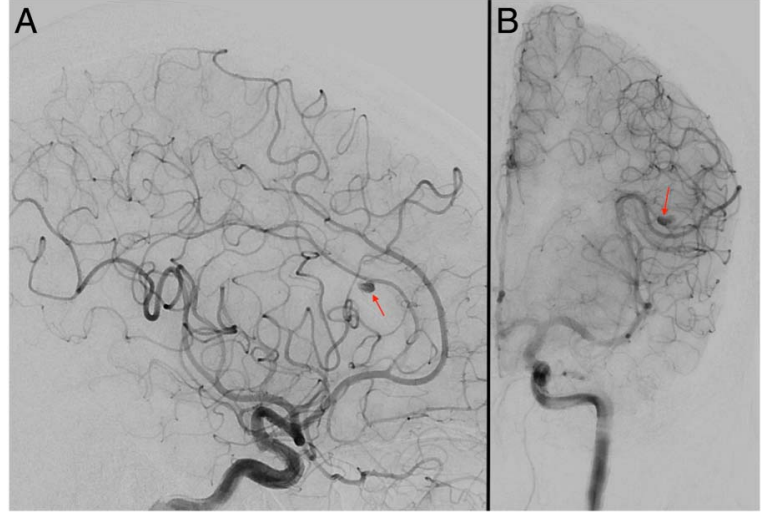

Figure 4 (A) Lateral and (B) anterior-posterior views of a sidewall middle cerebral artery aneurysm (arrows) seen during digital subtraction angiography.

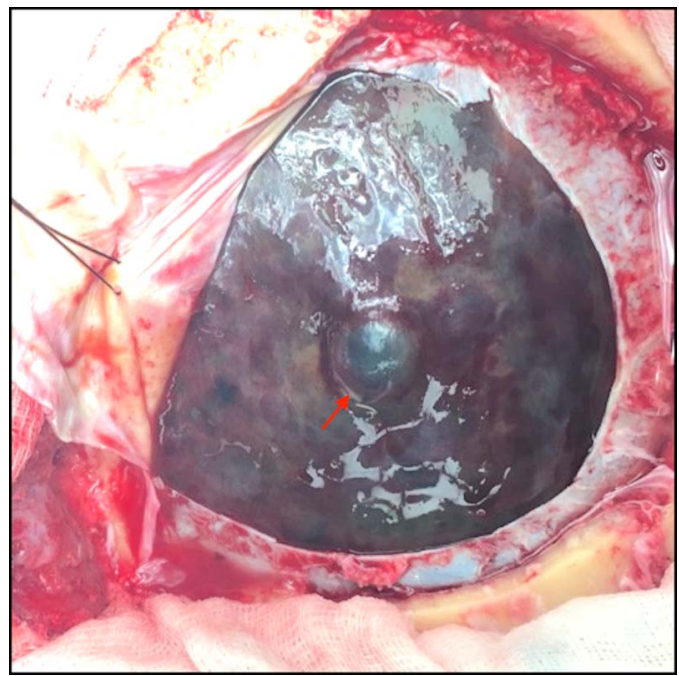

Figure 5 Intraoperative appearance of aneurysm (arrow) seen following durotomy.

usually in association with skull fracture. ${ }^{3}$ Owing to their location, 55\% of TMCAA present with $\mathrm{SDH}^{3}$ About $83.3 \%$ are pseudoaneurysms resulting from complete transmural injury of the artery. $^{2} 3$ In a review of 28 cases of 32 traumatic MCA aneurysms, delayed rupture occurred in $46.7 \%$ of patients, an average of 4.7 days following injury. ${ }^{3}$ Two patients in this review had multiple TMCAA; all were ipsilateral and were found along linear parietal bone skull fractures. TMCAA are usually amenable to surgical trapping and excision without compromise of distal bloodflow. ${ }^{3}$

Patients with delayed neurological deterioration following head injury should undergo cerebral angiography to investigate for TICA, and if found, early surgical intervention is recommended to prevent rebleeding.

\section{Learning points}

- Traumatic middle cerebral artery aneurysm (TMCAA) can occur following head trauma, and rupture of the aneurysm can result in subdural haematoma.

- TMCAA can cause delayed bleeding, manifesting as new neurological deficit some days following head injury.

- TMCAA can be effectively treated with surgical trapping and excision without compromising distal blood flow.

Contributors LB, PS and SV contributed equally to the composition of this 'Images in...' Case Report. All three were involved in the direct clinical care of the patient described, and the authors subsequently shared the load of review of clinical material, writing, figure creation, editing and review.

Competing interests None declared.

Patient consent Obtained.

Provenance and peer review Not commissioned; externally peer reviewed.

\section{REFERENCES}

1 Ventureyra EC, Higgins MJ. Traumatic intracranial aneurysms in childhood and adolescence. Case reports and review of the literature. Childs Nerv Syst 1994; 10:361-79.

2 Bhaisora KS, Behari S, Godbole C, et al. Traumatic aneurysms of the intracranial and cervical vessels: a review. Neurol India 2016;64:14-23.

3 Horiuchi T, Nakagawa F, Miyatake M, et al. Traumatic middle cerebral artery aneurysm: case report and review of the literature. Neurosurg Rev 2007;30:263-7.

Copyright 2017 BMJ Publishing Group. All rights reserved. For permission to reuse any of this content visit

http://group.bmj.com/group/rights-licensing/permissions.

BMJ Case Report Fellows may re-use this article for personal use and teaching without any further permission.

Become a Fellow of BMJ Case Reports today and you can:

- Submit as many cases as you like

- Enjoy fast sympathetic peer review and rapid publication of accepted articles

- Access all the published articles

- Re-use any of the published material for personal use and teaching without further permission

For information on Institutional Fellowships contact consortiasales@bmjgroup.com

Visit casereports.bmj.com for more articles like this and to become a Fellow 